\title{
HUB KREATIF AUDIO DAN VISUAL DI KEBAYORAN BARU
}

\author{
Yoshua Triwisnu Haryanto ${ }^{1)}$, Suwandi Supatra ${ }^{21}$ \\ 1) Program Studi S1 Arsitektur, Fakultas Teknik, Universitas Tarumanagara, yoshua.yth@gmail.com \\ 2) Program Studi S1 Arsitektur, Fakultas Teknik, Universitas Tarumanagara, ybhan50@gmail.com
}

Masuk: 14-07-2020, revisi: 31-07-2020, diterima untuk diterbitkan: 24-09-2020

\begin{abstract}
Abstrak
Jakarta yang menjadi pusat perekonomian negara sedang mengalami Bonus Demografi dan Revolusi Industri 4.0. Di mana jika kedua fenomena ini dikelola dengan baik maka akan membawa dampak positif bagi Indonesia, terutama Jakarta. Namun hal ini mengancam para pekerja dengan jenis pekerjaan yang repetitif dan para penduduk di usia produktif. Industri kreatif merupakan salah satu contoh dari pekerjaan yang tidak repetitif, dan masih butuh pengembangan di bidang tersebut. Proyek ini bertujuan agar terciptanya ruang interaksi sosial di dalam Kecamatan Kebayoran Baru dalam wadah seni audio dan visual. Serta dalam membantu mengembangkan dan menyiapkan masyarakat dalam menghadapi tantangan dalam industri kreatif. Dalam melakukan penelitian ini, metode yang digunakan adalah: pertama, metode deskriptif yaitu melakukan studi literatur, observasi, dan dokumentasi. Kedua, metode metafora yaitu mengibaratkan Teater Wayang menjadi bentuk fisik arsitektur.
\end{abstract}

Kata kunci: Industri Kreatif; Revolusi Industri; Sosialisasi; Usia Produktif

\begin{abstract}
Jakarta, which is the center of the national economy, is facing Bonus Demographic and Industry Revolution 4.0 phenomenons. If both of these phenomena are well managed they will bring positive impacts to Indonesia, especially Jakarta. However these phenomenons threaten workers with repetitive types of works and civils at their productive age. The creative industry is one example of an unrepetitive work, and still needs development. This project aims to create social interaction space within the district of Kebayoran Baru via audio and visual arts. And in helping to develop and prepare communities to face challenges in the creative industry. In conducting this research, the methods used are: First, the descriptive method of conducting literature studies, observations, and documentation. Secondly, the metaphor method is metaphorizing Wayang Theater into a physical form of architecture.
\end{abstract}

Keywords: Creative Industries; Industry Revolution 4.0; Productive Age; Socialization

\section{PENDAHULUAN}

Indonesia saat ini sedang digempari dengan istilah Bonus Demografi dan Revolusi Industri 4.0. Jakarta yang menjadi pusat perekonomian negara akan terkena dampak langsung dari peristiwa ini. Menurut CNBC Indonesia, yang akan terkena dampak dari peristiwa ini adalah low skill workers dan mereka menduduki usia 15-64 tahun. Peristiwa seperti ini jika dapat dikelola dengan baik tentu akan membawa dampak positif bagi Indonesia. Sebaliknya jika tidak dikelola dengan baik akan menjadi masalah besar dan beban bagi negara. Sehingga dibutuhkannya tempat atau wadah yang dapat mengelola sumber daya manusia sehingga menciptakan penduduk yang lebih produktif.

Bonus Demografi merupakan masa di mana angka beban ketergantungan antara penduduk usia produktif dengan penduduk usia tidak produktif paling rendah. Jadi setiap penduduk usia 
kerja menanggung sedikit penduduk usia tidak produktif (Yayak, 2015:87). Menurut Badan Pusat Statistik, Jakarta Selatan sedang mengalami Bonus Demografi dengan rasio ketergantungan sebesar 40,99\% dan dengan jumlah penduduk produktif sebesar 70,92\%. Tentunya hal ini harus diolah dengan baik agar tidak menjadi masalah bagi perekonomian Indonesia.

Sedangkan Revolusi Industri 4.0 menurut Schwab (2017) merupakan tahapan dalam pembangunan pengetahuan di mana batas antara dunia fisikal, digital, dan biologi semakin mengabur. Atau bisa dikatakan bahwa revolusi industri 4.0 adalah bagaimana teknologi seperti kecerdasan buatan, kendaraan otonom, dan internet saling mempengaruhi kehidupan manusia. Periode ini akan menjadi ancaman besar bagi para profesi dengan jenis pekerjaan yang repetitif karena dapat dengan mudah tergantikan oleh teknologi otonom. Namun menurut CNBC Indonesia, salah satu profesi yang akan bertahan pada era ini adalah profesi di bidang industri kreatif.

Tentunya dengan pengolahan sumber daya manusia yang baik pada saat terjadinya bonus demografi terutama di industri kreatif, diharapkan dapat membantu Indonesia dalam bersaing dengan negara-negara lain dalam perekonomian. Langkah yang harus dilakukan adalah dengan menyediakan wadah masyarakat dalam mengolah keterampilan maupun menunjukan bakatnya. Sehingga masyarakat siap masuk ke jenjang yang lebih luas.

\section{KAJIAN LITERATUR}

\section{Open Architecture}

Ruang dapat bertransformasi menjadi tempat ketika ruang tersebut memperoleh arti dan nilai (Yi Fu Tuan, 1977:136). Bisa dikatakan bahwa jika individu mengalami sebuat ruang, maka individu tersebut bisa menangkap nilai-nilai yang hadir pada ruang tersebut. Nilai ini kemudian yang menentukan apakah ruang tersebut dapat dikatakan tempat atau tidak, bagaimana kondisi yang abstrak bisa menjadi terdefinisikan.

Menurut De Certeau, "Space is practiced place. Thus the street geometrically defined by urban planning is transformed into a space by walkers" (De certeau, 1984:124). Atau kata lainnya adlaah tempat menjadi dasar dari kehadiran sebuah ruang.

\section{Third Place}

Ray Oldenburg mengungkapkan bahwa third place adalah tempat di mana seseorang menghabiskan waktunya antara rumah (first place) dan tempat kerja (second place). Third place merupakan tempat dimana pertukaran ide, tempat di mana seseorang bisa bersenang-senang, dan membangun hubungan. Bisa dikatakan bahwa third place merupakan tempat di mana kita bisa bersantai di publik, dan dapat bertemu dengan orang lain baik dikenal maupun tidak dikenal. Menurut Oldenberg third place memiliki delapan karakter yaitu: neutral ground, leveler, conversation is the main activity, accessibility and accomodation, the regulars, a low profile, the mood is playful, a home away from home.

\section{Industri Kreatif}

Menurut Badan Ekonomi Kreatif 2017 jika dilihat dari ruang lingkup industri kreatif, lima bidang dengan laju pertumbuhan subsektor EKRAF tertinggi adalah sebagai berikut: desain komunikasi visual, televisi dan radio, musik, seni pertunjukan, dan film. Namun dalam memanfaatkan dan mengembangkan kelima bagian dari industri kreatif tersebut juga terdapat beberapa masalah yang dihadapi seperti: Riset dan pengembangan, edukasi, infrastruktur fisik, serta pemasaran dalam negeri. 

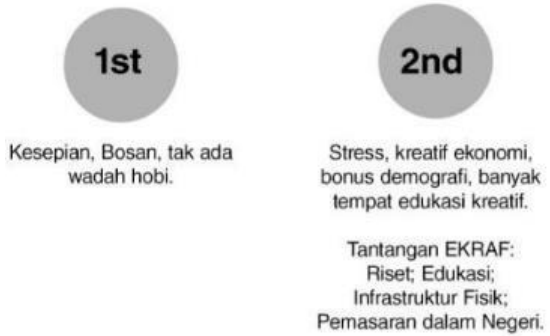

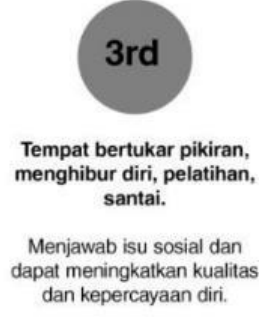

3rd

Tempat bertukar pikiran, diri, pelatihan, at meningkatkan kualitas dan kepercayaan dir

Gambar 1. Kebutuhan akan third place (Sumber: Penulis, 2020)

Dari ketiga hal di atas dalam merencanakan proyek, proyek harus memiliki sifat dari pada third place itu sendiri serta menjawab dari isu-isu yang sudah dibahas terutama masalah yang terjadi di industri kreatif. Serta diharapkan dengan mengangkat isu industri kreatif, pemikiran masyarakat dapat lebih terbuka dengan terbentuknya ruang bertukar pikiran yang disediakan dalam bentuk wadah arsitektur.

\section{METODE}

Metode yang digunakan dalam pembahasan ini adalah secara desktriptif dengan mengidentifikasi data dan teori terkait yang bersifat kualitatif maupun kuantitatif yang kemudian dianalisa untuk memperoleh program. Pengumpulan data dilakukan dengan cara studi literatur, survei, dan studi preseden. Metode ini digunakan untuk mengumpulkan data primer dan sekunder. Lalu metode tersebut digabungkan dengan metode metafora, yaitu mengibaratkan suatu ide yang dituang ke dalam suatu ide baru.

Teater wayang merupakan pagelaran seni audio dan visual khas Jawa. Dalam pagelaran ini terdapat beberapa elemen penting yang mendukung terjadinya suatu pagelaran yaitu: Dalang, Wayang, Layar, dan Penonton. Setiap elemen tersebut memiliki peran seperti dalang yang memainkan wayang, wayang yang menjadi pemeran, layar yang menjadi elemen pemisah serta bidang yang menjadi media, penonton sebagai pendatang yang ingin menghilangkan kesuntukan. Oleh karena itu, Teater Wayang diambil dan dimetaforakan menjadi sebuah ide baru yang dituangkan dalam bentuk arsitektur pada proyek ini.

\section{DISKUSI DAN HASIL}

Dari penggabungan antara data dan fenomena yang terjadi di kawasan Kebayoran Baru, kebutuhan akan third place berupa wadah edukatif dan hiburan. Pada third place orang melarikan diri dari first place dan second place untuk membuka jati dirinya dan bertujuan untuk bersosialisasi di dalamnya.

Dari kebutuhan akan third place dengan kebutuhan dari penduduk sekitar dan digabungkan dengan isu industri kreatif dan bonus demografi yang menjadi latar bekalang permasalahan dapat diwujudkan dalam bentuk beberapa aktivitas seperti musik, tari, diskusi, menonton, santai, pemasaran, pameran, nongkrong, edukasi, dan pentas.

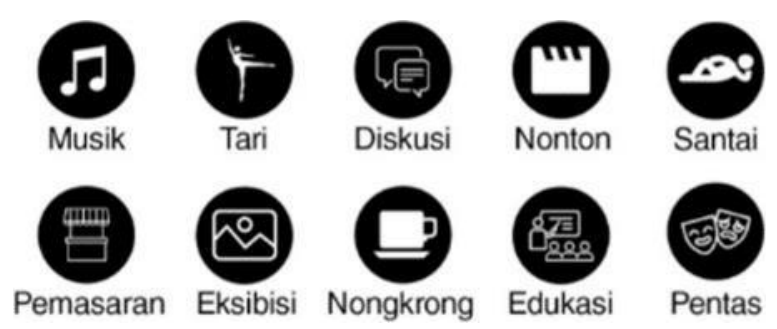

Gambar 2. Aktivitas (Sumber: Penulis, 2020) 
Lalu hasil dari pengolahan data di atas dipadukan dengan metode metafora dari teater wayang. Di mana dalam teater wayang terdapat empat elemen penting yaitu: Dalang, sebagai yang dihormati dalam kebudayaan Indonesia akan pengetahuan dan spiritualya; Wayang, karakter dalam teater wayang yang dalam bahasa Jawa berarti "bayangan"; Layar, elemen pemisah antara pemain dan penonton serta menjadi tempat jatuhnya bayangan; penonton, penikmat teater wayang. Dari deskripsi dari masing-masing elemen tersebut dapat dimetaforkan menjadi pembagian zoning dan hirarki dalam pembentukan massa bangunan seperti berikut:
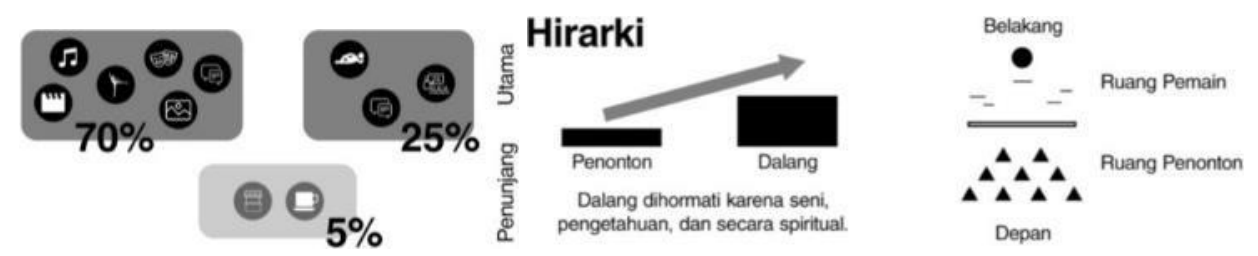

Gambar 3. Zoning dan Hirarki

Sumber: Penulis, 2020
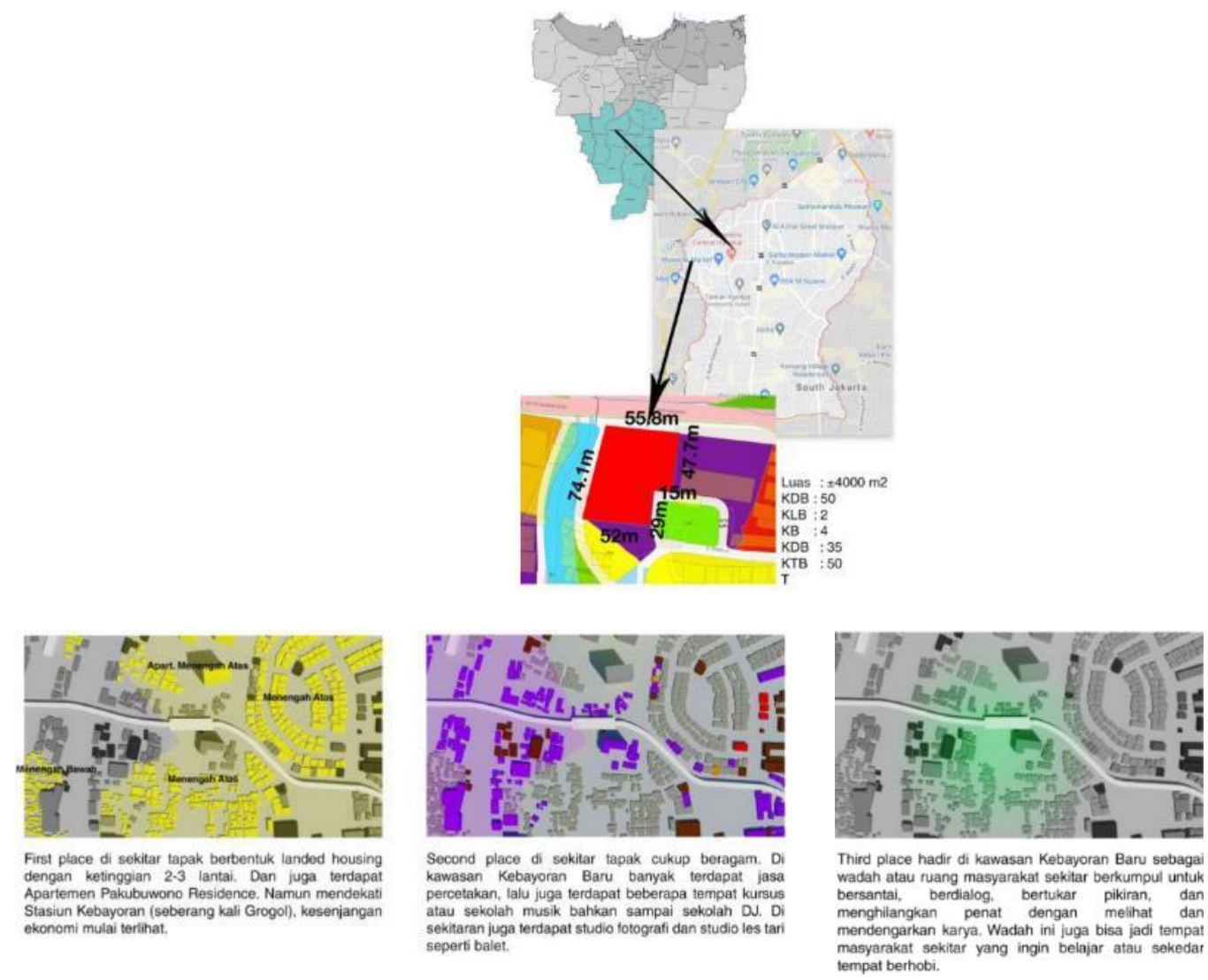

Gambar 4. Karakteristik Tapak

Sumber: Penulis, 2020

Tapak berada di kawasan Kebayoran Baru Jakarta Selatan, tepatnya di Jalan Kebayoran Baru. Tapak berbatasan dengan kali Grogol pada sisi barat. Tapak dilalui oleh moda transportasi publik Transjakarta dan berjarak kurang dari 10 menit dari KRL Stasiun Kebayoran. Tapak dikelilingi oleh first place yang berbentuk landed house dan vertical 
housing, di mana mayoritas merupakan masyarakat menengah atas. Dan pada ruas jalan dan sisi barat tapak terdapat second place dalam bentuk sekolah musik, sekolah DJ, sekolah tari, serta tempat percetakan maupun studio fotografi.

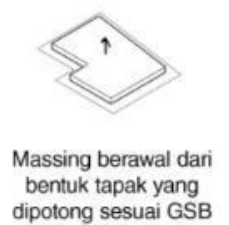
bentuk tapak yang
dipotong sesuai GSB

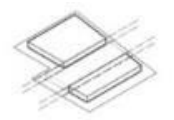

Massing dibagi dua agar terbentuk nuang luar

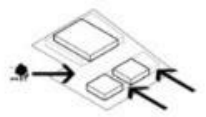

Akses masuk ad tiga, yang sisi tenggara dengan rukan, massa untuk renaca zonasi belakang dengan jalur bus

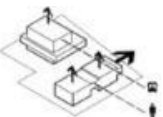

Antar

Gambar 5. Proses Gubahan Massa

Sumber: Penulis, 2020

Proses pembentukan gubahan massa diawali oleh mengikuti bentuk tapak, lalu dibagi menjadi dua agar terbentuknya ruang luar. Pada bagian tapak yang bersinggungan langsung dengan Jl. Kebayoran Baru dijadikan akses masuk utama, di mana terdapat akses pengunjung, akses drop-off dan parkir service, serta untuk parkir sepeda. Sedangkan pada sisi tenggara diberikan akses pengunjung dari penduduk sekitar, karena menurut zonasi akan dibuatkan ruang terbuka hijau dari arah tenggara. Tinggi massa disesuaikan dengan hirarki yang mana juga sejajar dengan bangunan seberang tapak untuk massa bagian depan dan sejajar dengan jembatan transportasi umum Transjakarta untuk massa bagian belakang. Lalu antar massa diberi penghubung.

Berikut hasil rancangan untuk proyek tersebut:

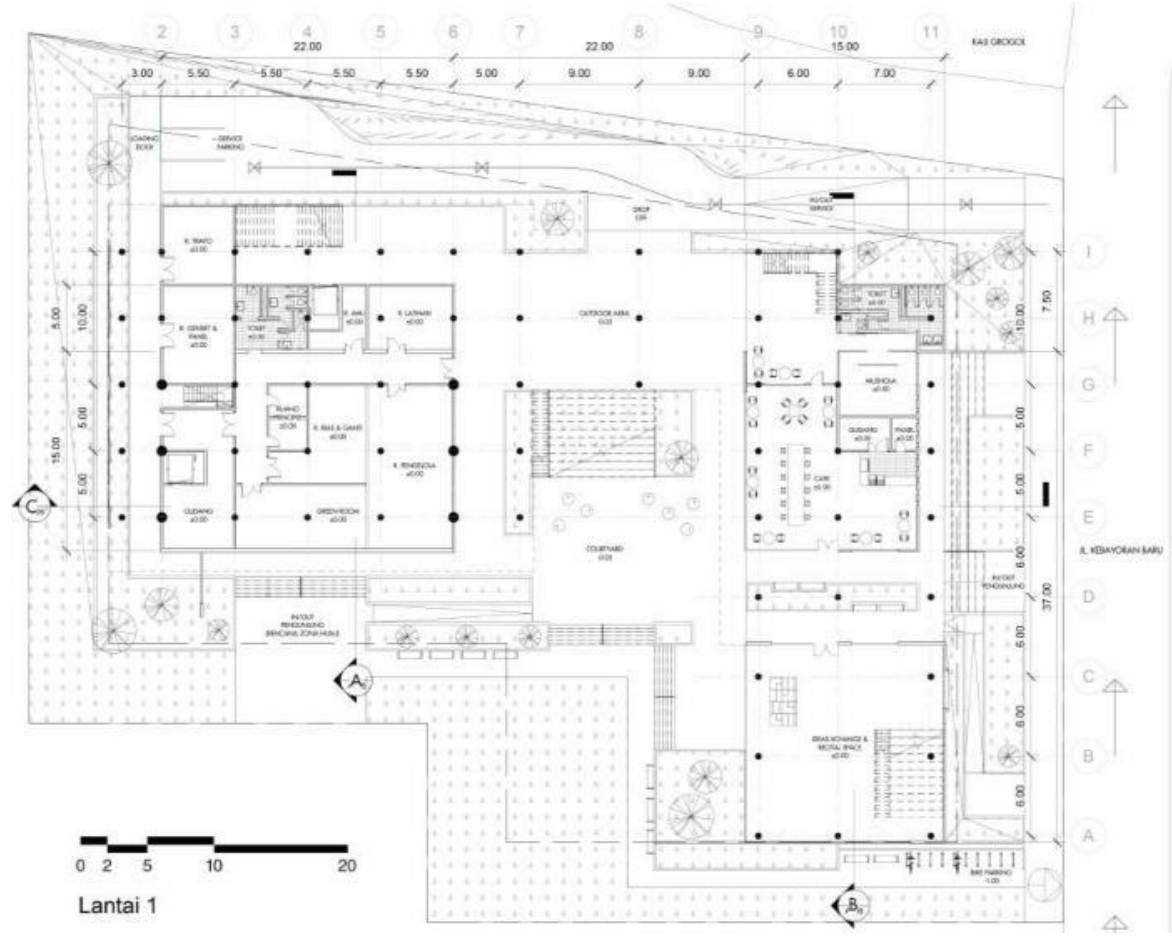

Gambar 6. Denah

Lantai 1

Sumber: Penulis, 2020 


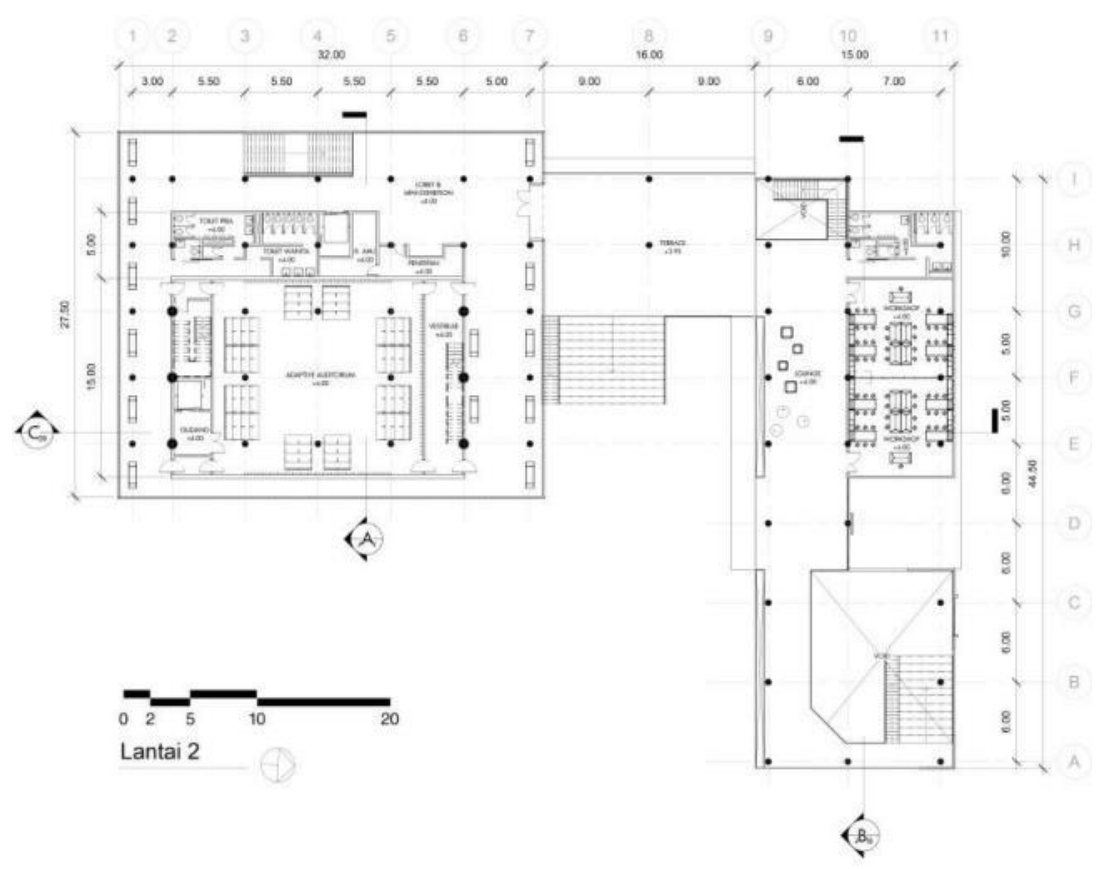

Gambar 7. Denah Lantai 2

Sumber: Penulis, 2020

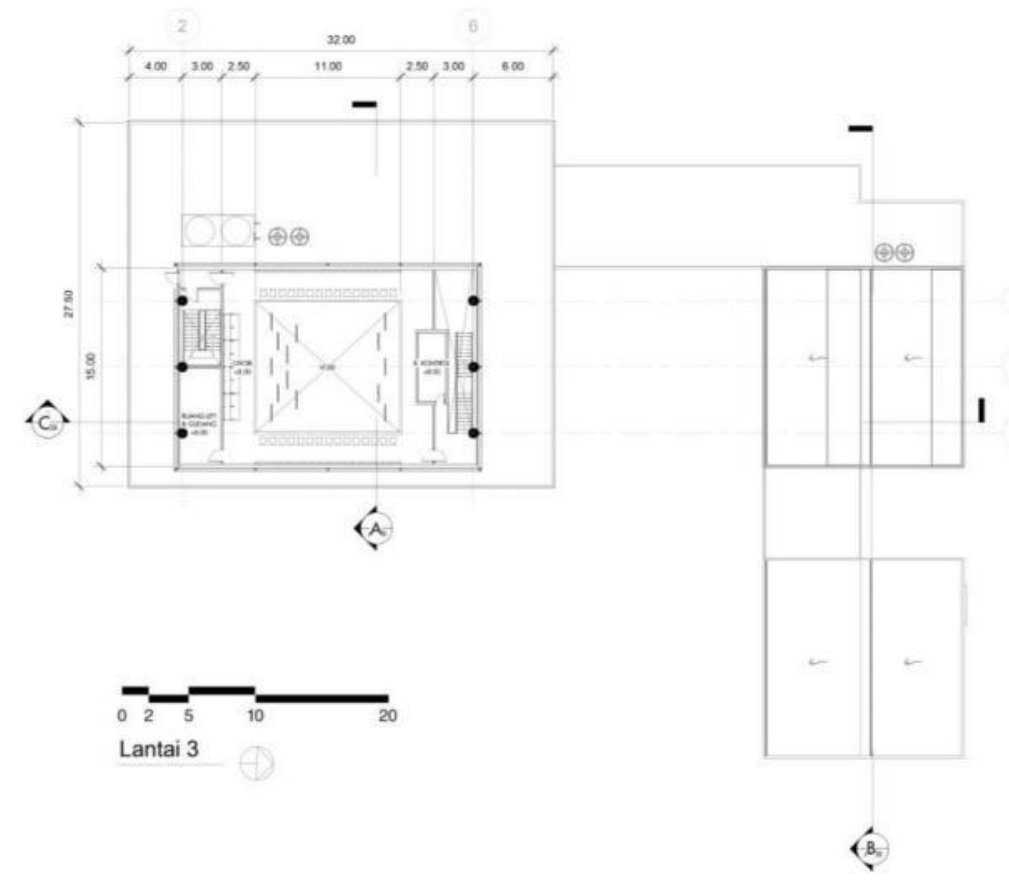

Gambar 8. Denah Lantai 3

Sumber: Penulis, 2020

\section{KESIMPULAN DAN SARAN}

\section{Kesimpulan}

Berdasarkan kebutuhan tersebut, proyek ini memiliki beberapa aktivitas utama yaitu:

a. Adaptive-Auditorium yang dapat memenuhi berbagai kegiatan karena layout tempat duduk yang dapat diubah sesuai kebutuhan;

b. Edukasi dengan tersedianya kegiatan belajar, mengembangkan diri, dan ruang workshop; 
c. Sosial dan santai dengan tersedianya banyak tempat untuk saling berinteraksi satu sama lain;

d. Market Place yaitu sebuah event yang dapat diadakan di dalam tapak yang tujuannya untuk memperkenalkan hasil karya ke masyarakat luas.

\section{Saran}

Saran pada proyek ini diberikan kepada masyarakat untuk lebih berani bereskpresi dan mengapresiasi suatu karya seni dalam bentuk apapun.

\section{REFERENSI}

De Certeau, M. (1984). The practice of everyday life University of California Press. Berkeley CA.

Djoko, M. S., Karyana, Y., Karim, N. A., Mirdad, A. J., Fatah, R. H. A., Kusdiana, D., dan Badranaya, D. (2017). Mobilitas Penduduk dan Bonus Demografi. UNPAD PRESS.

Fitriati, R. (2015). Menguak Daya Saing UMKM Industri Kreatif: Sebuah Riset Tindakan Berbasis Soft Systems Methodology. Yayasan Pustaka Obor Indonesia.

Sukmaningrum, A. (2017). Memanfaatkan Usia Produktif Dengan Usaha Kreatif Industri Pembuatan Kaos Pada Remaja Di Gresik. Paradigma, 5(3).

Tuan, Y. F. (1977). Space and place: The perspective of experience. $U$ of Minnesota Press. Wijatno, S. (2009). Pengantar entrepreneurship. Grasindo. 
